\title{
Small-Size Effects on Electron Transfer in P3HT/InP Quantum Dots
}

\author{
Jun Yin, ${ }^{\dagger}$ Manoj Kumar, ${ }^{\dagger}$ Qiong Lei, ${ }^{\ddagger}$ Lin Ma, ${ }^{\dagger}$ Sai Santosh Kumar Raavi, ${ }^{\dagger}{ }^{\S}$ Gagik G. Gurzadyan, ${ }^{\dagger}$ \\ and Cesare Soci* ${ }^{\dagger}$ \\ ${ }^{\dagger}$ Division of Physics and Applied Physics, School of Physical and Mathematical Sciences, Nanyang Technological University, 21 \\ Nanyang Link, Singapore, Singapore, 637371 \\ ${ }^{\ddagger}$ Division of Chemistry and Biological Chemistry, School of Physical and Mathematical Sciences, Nanyang Technological University, \\ 21 Nanyang Link, Singapore, Singapore, 637371
}

Supporting Information

ABSTRACT: The charge carrier photogeneration yield in hybrid polymer/nanocrystal solar cells strongly depends on the interplay between charge transfer across quantum dot (QD) organic capping layers and quantum confinement effects related to the QD size. Here we combine femtosecond transient spectroscopy and density functional theory (DFT) calculations to improve the understanding of charge transfer dynamics at P3HT/ InP QD heterointerfaces as a function of core size $(2.5 \mathrm{vs} 4.5 \mathrm{~nm})$ and length of the surface ligands (oleylamine vs pyridine). We find that, for large core QDs, the polaron generation yield in P3HT is enhanced by efficient exciton dissociation and charge transfer, and is limited by the length of the ligands. Conversely, for smaller size QDs, electron injection from P3HT to InP cores becomes inefficient due to the unfavorable interfacial energetics, even with short pyridine ligands. Thus, we suggest that both QD surface ligand functionalization and core size should be optimized simultaneously for the design of highperformance hybrid nanocrystal/polymer solar cells.

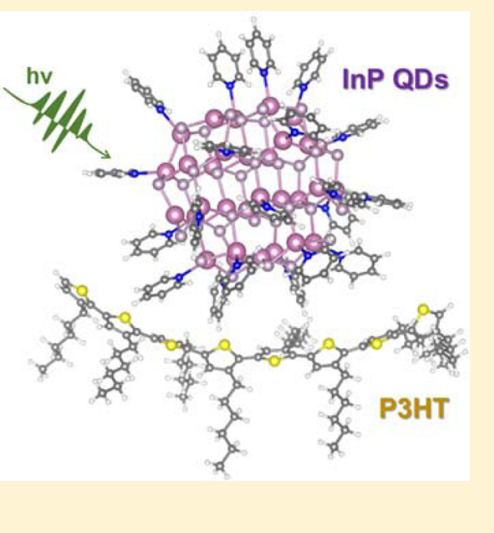

\section{INTRODUCTION}

Hybrid organic/inorganic solar cells combining organic conductive polymers and inorganic nanocrystals have been developed in recent years as an alternative to all-organic solar cells. ${ }^{1,2}$ The possibility of replacing fullerene derivatives, commonly used as acceptors in organic solar cells, with nanostructured inorganic semiconductors offers benefits of tunable absorption and emission spectra, particularly in the near-infrared spectral range, higher charge carrier mobility, ${ }^{3}$ multiple exaction generation ${ }^{4}$ and better thermal- and photostability. ${ }^{5}$ Meanwhile, the high dielectric constant of inorganic nanocrystals assists charge separation and suppresses recombination at the organic/inorganic interfaces. ${ }^{6}$ Various composites based on $\mathrm{Si}^{7,8} \mathrm{ZnO},{ }^{9} \mathrm{CdSe},{ }^{10-12} \mathrm{PbS},{ }^{13-15}$ and a few other IIVI and III-V nanocrystals are currently studied from both experimental and theoretical standpoints. Nevertheless, the power conversion efficiency of quantum dots (QDs)/polymer solar cell remain quite low compared to purely organic counterparts ( $\mathrm{Si}, 1.1 \%{ }^{7} \mathrm{CdSe}, 3.6 \%{ }^{16} \mathrm{CdSe}, \sim 4 \% ;{ }^{17} \mathrm{PbS}$, $\left.4.23 \%^{18}\right)$. For these hybrid systems, the choice of QDs size and organic molecules used for coating QDs governs the optical behavior of inorganic cores and influences the performance of QDs-based photovoltaic devices. ${ }^{19}$ On one hand, the organic ligands passivating the surface of quantum dots (QDs) can exert considerable influence over their photophysical and charge or energy transfer properties when mixed with low bandgap polymers, such as $\mathrm{P} 3 \mathrm{HT}$, poly(3-hexylthiophene-2,5diyl). For example, the long alkane ligands (e.g., trioctylphosphine oxide and oleylamine) required to stabilize the colloid can be replaced with shorter ligands to reduce the distance between QDs and polymer chains. ${ }^{20}$ On the other hand, reducing the QDs size allows exploiting quantum confinement effects to adjust energy levels to match with frontier orbital energy of polymers and form type-II hybrid heterojunctions that promote charge separation. ${ }^{21}$ For instance, the external quantum efficiency of hybrid solar cells was found to decrease by increasing the core size of $\mathrm{PbS} \mathrm{QDs}$ blended with conjugated polymer PTB1. ${ }^{21}$ In extremely small QDs, however, charge transfer may be inhibited by unfavorable energy alignment, particularly upon ligand exchange. Thus, quantum size effect, which controls the spread of the wave function outside the QD core, must also be carefully considered to improve the photovoltaic performance of hybrid blends. ${ }^{22,23}$

III-V QDs display size-tunable absorption and emission in a wide range of the visible spectrum, and are somehow less toxic than typical II-VI QDs containing Cd or Se elements. ${ }^{24}$ In particular, InP QDs are known to exhibit a range of liganddependent behavior and provide an ideal system for investigating the underlying photophysical and charge transfer mechanisms. However, partly due to the difficulty in the synthesis of III-V QDs compared to other types of inorganic QDs, ${ }^{25}$ few works on the organic ligand effects on the electronic band energies and ultrafast charge transfer dynamics between QDs and low bandgap polymers have been

Received: September 26, 2015

Revised: November 5, 2015

Published: November 6, 2015 

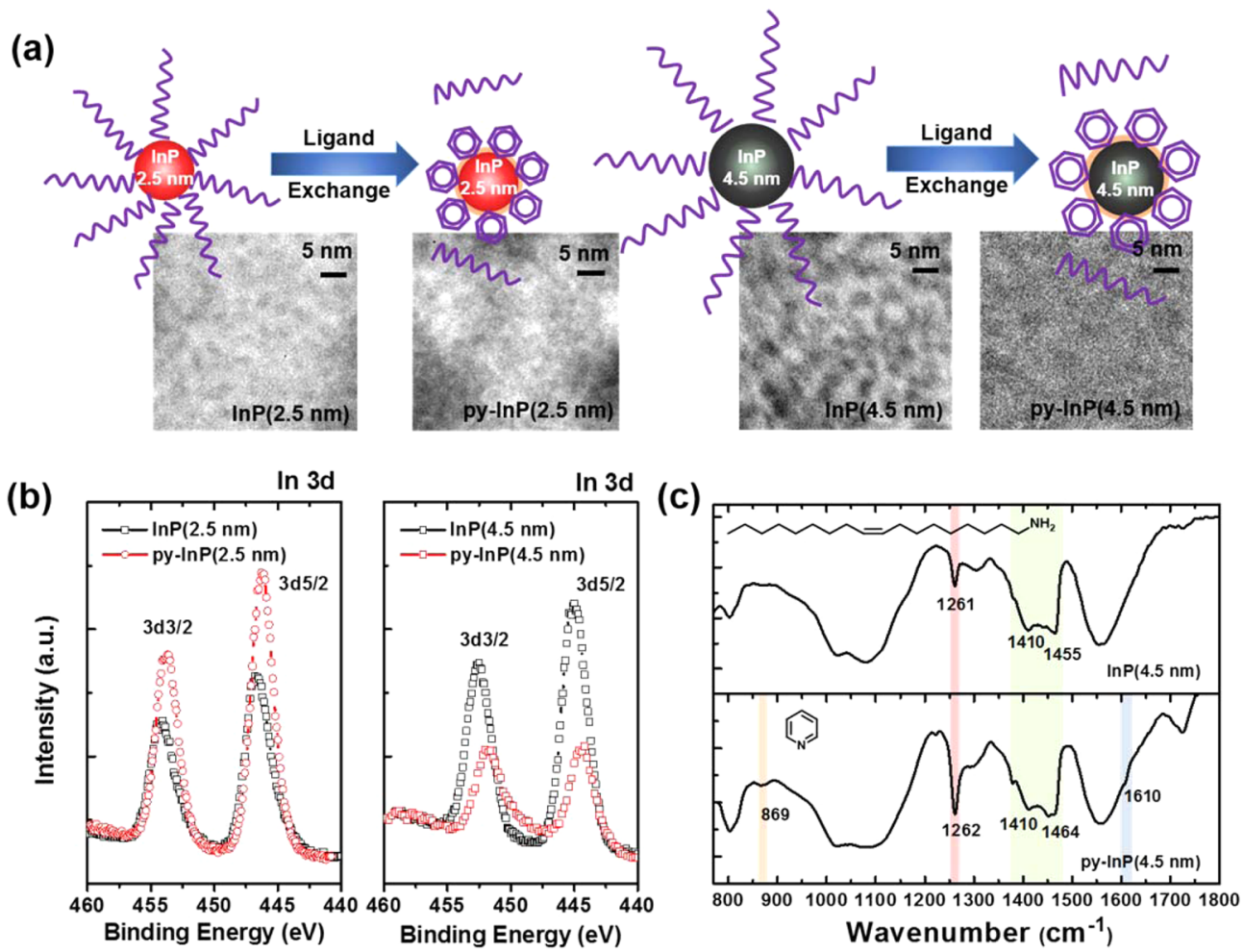

Figure 1. (a) TEM images of InP QDs encapsulated with oleylamine and pyridine ligands, after the oleylamine to pyridine ligand exchange process shown in the schematics. (b) XPS of In 3d orbitals and (c) FTIR transmittance spectra of InP QDs, capped with oleylamine and pyridine ligands.

reported. $^{26,27}$ Blackburn et al. demonstrated the successful injection of electrons into the conduction band of InP QDs and the relaxation rate of $1 \mathrm{P}-1 \mathrm{~S}$ increases with decreasing InP QD size. ${ }^{28}$ Hole transfer from photoexcited InP QDs to the hole acceptor TMPD molecule and electron transfer to nanocrystalline $\mathrm{TiO}_{2}$ films were also examined by time-resolved transient absorption measurements. ${ }^{29}$ Selmarten et al. showed that the polymer and InP QD can form a stable complex and the excited InP QD transfers its hole to the conductive polymer. ${ }^{30}$ In theory, quantitative understanding of interfacial charge transfer processes of hybrid molecular systems have been well described by the Marcus theory based on $a b$ initio calculations. Wu et al. studied dangling bonds effect on the charge transfer processes in hybrid silicon quantum dots/P3HT system. ${ }^{31}$ Wang et al. demonstrated that hole transfer from the $\mathrm{CdSe} / \mathrm{CdS}$ quantum rod to the tethered ferrocene moiety is in the inverted region of Marcus theory. ${ }^{32}$

Here we combine a variety of spectroscopy measurements and quantum chemical calculations to examine the combined effects of size and organic ligands on the electronic properties of InP QDs and charge transfer processes in hybrid InP QDs/ $\mathrm{P} 3 \mathrm{HT}$ thin films. We observe an instantaneous creation of singlet excitons that subsequently dissociate to form polarons on an ultrafast time scale; the yield of polaron formation is significantly enhanced by adding InP QDs as electron acceptors. The enhancement of polaron absorption upon photoexcitation proves that electron injection from P3HT into $4.5 \mathrm{~nm}$, pyridine ligand-capped InP QDs is very efficient due to large electronic coupling between the lowest unoccupied molecular orbital (LUMO) level of P3HT and the conduction band $(\mathrm{CB})$ of InP QDs. On the other hand, in the $2.5 \mathrm{~nm} \operatorname{InP}$ $\mathrm{QDs} / \mathrm{P} 3 \mathrm{HT}$ system, electron injection is rather inefficient and back energy transfer is possible because of the overlap between the emission spectrum of P3HT and the absorption of $2.5 \mathrm{~nm}$ InP QDs. These findings supplement our understanding of interfacial charge transfer dynamics between small QDs and organic semiconductors, and can assist the rational design of functional nanocrystals.

\section{RESULTS AND DISCUSSION}

Given the extremely large surface to volume ratio, the electronic properties of QDs are strongly dependent on surface functionalization. ${ }^{33,34}$ In this work, the long ligand (oleylamine) used to stabilize colloidal dispersions of InP QDs and prevent their aggregation was replaced by a short ligand (pyridine) to reduce the spacing between InP core and P3HT polymer chains in hybrid photovoltaic blends (Figure 1a). Different from common ligand-exchange methods for II-VI QDs, here methanol was used to precipitate the InP cores instead of the less-polar hexanes (see experimental section for details on ligand exchange). Low resolution transmission electron microscopy (LR-TEM) images recorded before and after ligand exchange reveal that the average radii of original InP QDs were 2.5 and $4.5 \mathrm{~nm}$, and that QDs retain almost the same size after ligand exchange (Figure 1a). ${ }^{35} \mathrm{X}$-ray photoelectron spectroscopy (XPS) and FTIR transmittance spectra measurements were used to determine the elemental composition and chemical bonding of InP QDs with different ligands. As shown in Figure $1 \mathrm{~b}$, the In $3 \mathrm{~d}$ XPS spectrum exhibits two contributions, $3 d_{5 / 2}$ and $3 d_{3 / 2}$, respectively located at 447 and $454 \mathrm{eV}$, which are subject to a rather small shift (less than 1 $\mathrm{cm}^{-1}$ ) due to formation of $\mathrm{In}-\mathrm{N}$ (pyridine) bonds upon ligand exchange. This suggests that $\mathrm{N}$ atoms bind much stronger to In rather than to $\mathrm{P}$ atoms, in agreement with previous findings by Dung et al. ${ }^{36}$ Nevertheless, in $\operatorname{InP}(4.5 \mathrm{~nm})$ the red shift of the $3 d_{5 / 2}$ and $3 d_{3 / 2}$ peaks is larger than in $\operatorname{InP}(2.5 \mathrm{~nm})$, most likely 
due to the high binding efficient of pyridine on the surface. The $\mathrm{P} 2 \mathrm{p}$ spectrum shown in Figure $\mathrm{S} 1$ indicates the presence of two chemical environments for the $\mathrm{P}$ atoms: the predominant peak, with binding energy below $130 \mathrm{eV}$, is characteristic of InP; the other peak, located at higher binding energies (133.2$134.1 \mathrm{eV})$, can be attributed to the phosphorus in an oxidized environment $\left(\mathrm{InPO}_{x}\right){ }^{37}$ The FTIR spectrum in Figure 1c shows two bands between 1100 and $1200 \mathrm{~cm}^{-1}$, which can be attributed to the $\mathrm{P}=\mathrm{O}$ stretching mode corresponding to phosphine oxide. ${ }^{38}$ The vibrational signatures confirm the success of ligand-exchange with pyridine, with clear signatures of the $\mathrm{C}=\mathrm{CH}$ out of plane vibration at $869 \mathrm{~cm}^{-1}$, and $\mathrm{C}=\mathrm{N}$ stretching mode at $1610 \mathrm{~cm}^{-1}$, proving that $\mathrm{N}$ in pyridine was successfully bounded to the InP QD surface after ligand exchange. The oleylamine ligands are not fully removed as indicated by the appearances of stretching modes at 962 and $1072 \mathrm{~cm}^{-1}$ ( $\mathrm{C}=\mathrm{C}$ stretching), and $1262 \mathrm{~cm}^{-1}(\mathrm{C}-\mathrm{N}$ stretching).

Methylamine $\left(\mathrm{NH}_{2} \mathrm{CH}_{3}\right)$ ligand modified $\mathrm{In}_{31} \mathrm{P}_{31}$ is a good reduced model for InP QDs chemically passivated by oleylamine ligand. Although the experimental band gap of InP QDs (2.5 and $4.5 \mathrm{~nm}$ ) cannot be reproduced using small size InP model, it still allows capturing the effects of different organic ligands and surface coverage on the electronic properties from computable point of view, which can provide guidance to design ligand-InP QDs complexes with proper energy levels. As shown in Figure 2a, the DFT results demonstrate that both type of organic ligands and surface coverage have significant influence on the HOMO and LUMO energy levels. For both methylamine and pyridine ligands, increasing the ligand coverage can destabilize both HOMO and LUMO levels. The band gap of $\operatorname{In}_{31} \mathrm{P}_{31}$ slightly reduces due to the surface reconstruction and introduction of midgap levels from pyridine segments capped on the surface. Figure $2 \mathrm{a}$ also shows the spatial electronic density distributions of HOMO and LUMO levels of the representative $\operatorname{In}_{31} \mathrm{P}_{31}$ with different organic ligands. It can be clearly seen that the HOMO mainly resides on the surface, representing the p-orbital character oriented to the (111) direction, while the LUMO is localized in the inner regions of $\operatorname{In}_{31} \mathrm{P}_{31}$ QDs, where most of the contributions of LUMO and HOMO stem from InP core atoms obtained from the projected density of state (PDOS, shown in Figure 2b). The methylamine ligands have little contribution to the density of states at the frontier energy region, but pyridine ligands contribute to the LUMO level of ligand-InP QD complex, where the HOMO is localized within the InP core and the LUMO is localized on pyridine. Electronic coupling between the pyridine HOMOs and the first state for hole $\left(1 S_{h}\right)$ of $\operatorname{In}_{31} P_{31}$ in the ground state of the complex create hybrid orbitals at the inorganic/organic interface. Such orbitals present a lower potential energy barrier, allowing holes to delocalize into the newly accessible states with mixed QDsurfactant character. ${ }^{22}$ Thus, the band gaps of InP QDs, directly affected by both HOMO and LUMO states, could loosely depend on the nonconjugated ligand species binding to the surface, but only on conjugated ligands, such as pyridine used here. The pyridine ligands are not expected to contribute to optical transition near the HOMO-LUMO gap energy, because the overlap of these LUMO wave function with the HOMO is negligible and optical transition into these states are expected to have small transition matrix elements. As shown in Figure S2, the photoluminescence of $2.5 \mathrm{~nm} \mathrm{InP} \mathrm{QDs} \mathrm{in}$ toluene solvent shows a slightly red-shift after pyridine
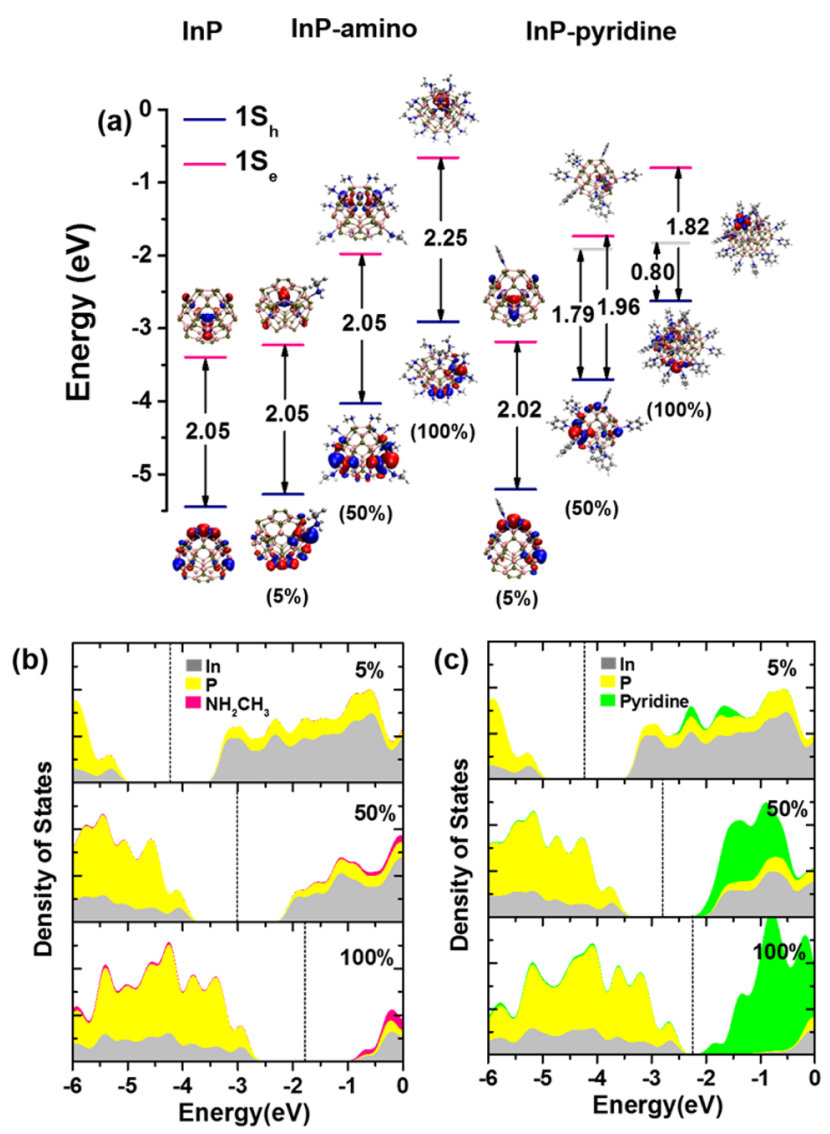

Figure 2. (a) Calculated energy level (HOMO and LUMO) of InP QDs with and without organic ligands (methylamine represents the oleylamine), for different coverage of In atoms (5\%, 50\% and 100\%); projected density of state (PDOS) on In (gray) and P (yellow) atoms with organic ligand (b) amino (purple) and (c) pyridine (green). The Fermi level (vertical dashed line) is chosen to be in the middle of the HOMO-LUMO gap.

replacement and enhancement of the emission peak at 700 $\mathrm{nm}$, possibly due to the presence of surface trap states. Conversely, for $4.5 \mathrm{~nm}$ QDs, the modest reduction in the average dot size during ligand-exchange becomes dominant, resulting in a slight blue shift of photoluminescence spectra after pyridine exchange.

The absorption spectra of P3HT, InP QDs capped with oleylamine and pyridine, and their InP/P3HT blends (weight ratio of 3:1) are shown in Figure 3a (left curves). The lowest energy absorption offsets, due to the lowest allowed transition $\left(1 \mathrm{~S}_{\mathrm{h}}-1 \mathrm{~S}_{\mathrm{e}}\right)$, occur from 530 to $640 \mathrm{~nm}$, in accordance with the size of InP QDs obtained by TEM. ${ }^{35}$ After mixing InP QDs with P3HT (black solid curve), the absorption spectra reflect the superposition of the absorption of individual components (P3HT and InP QDs). The photoluminescence spectra of these blends, obtained by photoexcitation at $500 \mathrm{~nm}$, are also shown in Figure 3a (right curves; note that emission intensity was normalized with respect to the absorbance at the excitation wavelength). The photoluminescence intensity of $\operatorname{InP}(4.5$ $\mathrm{nm}) / \mathrm{P} 3 \mathrm{HT}$ is found to be significantly reduced compared to pristine $\mathrm{P} 3 \mathrm{HT}$, especially in the case of $\mathrm{py}-\mathrm{InP}(4.5 \mathrm{~nm})$. It is possible that the oleylamine coating of the InP QDs quenches the photoluminescence as electron transfer occurs over a relatively small distance $(5-8 \AA)$. In the case of $\operatorname{InP}(2.5 \mathrm{~nm}) /$ $\mathrm{P} 3 \mathrm{HT}$, the photoluminescence intensity from $\mathrm{P} 3 \mathrm{HT}$ is even 

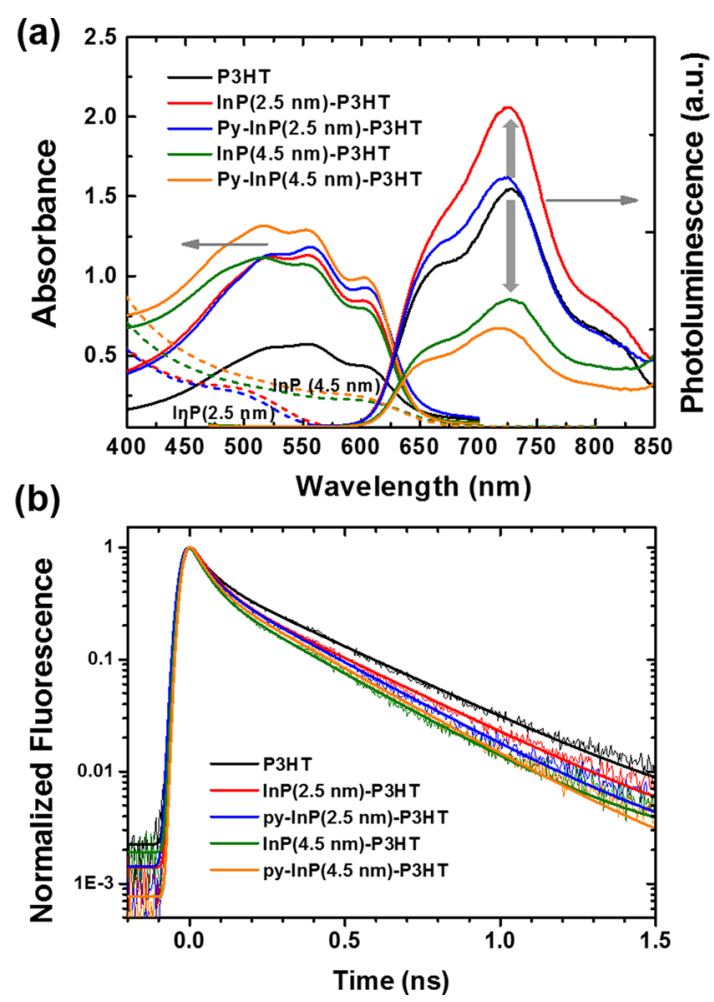

Figure 3. (a) Absorption (left) and photoluminescence (right) spectra of thin films of P3HT (solid black line), InP QDs (dashed lines) and InP QDs/P3HT blends (solid lines). (b) Time-resolved photoluminescence decay of thin films of P3HT and InP QDs/P3HT blends upon pulsed photoexcitation at $400 \mathrm{~nm}$.

higher than the pristine polymer, suggesting that electron injection from P3HT to $\operatorname{InP}(2.5 \mathrm{~nm})$ is inefficient. To deepen our understanding of exciton dynamics in $\operatorname{InP}(2.5 \mathrm{~nm})$ and $\mathrm{InP}(4.5 \mathrm{~nm})$ blended with $\mathrm{P} 3 \mathrm{HT}$, we conducted time-resolved photoluminescence measurements by time-correlated single photon counting (TCSPC), Figure 3b. All the samples were excited at $400 \mathrm{~nm}$, and emission was monitored at $650 \mathrm{~nm}$. The photoluminescence decays show a fast and a slow decay component, which were fitted by a double exponential function, $I(t)=a_{1} \exp \left(-\left(1 / \tau_{1}\right)\right)+a_{2} \exp \left(-\left(1 / \tau_{2}\right)\right)$ The extracted parameters are reported in Tables S1. For pristine P3HT, the fast decay component is $57 \mathrm{ps}$, while the slow decay component is 337 ps. The slow component agrees well with reported values of singlet exciton annihilation by monomolecular nonradiative or radiative processes. ${ }^{39}$ Photoluminescence lifetimes are shorter in $\mathrm{QD} /$ polymer blends due to effective exciton dissociation at the InP/P3HT heterointerfaces. The interfacial charge transfer efficiency can be estimated from the ratio between the exciton lifetime of $\mathrm{QD} / \mathrm{P} 3 \mathrm{HT}$ blends and that of pristine $\mathrm{P} 3 \mathrm{HT}$. The resulting efficiencies are $14.2 \%$ in py$\mathrm{InP}(2.5 \mathrm{~nm}) / \mathrm{P} 3 \mathrm{HT}$ and $17.8 \%$ in $\mathrm{py}-\mathrm{InP}(4.5 \mathrm{~nm}) / \mathrm{P} 3 \mathrm{HT}$. In agreement with DFT calculations, the py-InP $(4.5 \mathrm{~nm})$ QDs are more effective electron acceptors than the py- $\operatorname{InP}(2.5 \mathrm{~nm})$ QDs thanks to their proper energy alignment. To elucidate the origin of the fast decay components, we measured the fluorescence lifetime of our samples at $t<15$ ps by upconversion measurements (see Figure S3). Here the fast decay time is strongly sensitive to excitation intensity, and even at the lowest intensity needed to obtain a detectable signal $\left(I=8.5 \mathrm{~nJ} / \mathrm{cm}^{2}\right)$, the fluorescence lifetimes are reduced to only few picoseconds (refer to Table S2). This indicates that the fast fluorescence decays are due to diffusion-limited singlet-singlet annihilation. Similar bimolecular recombination effects were previously observed in PbS QDs/P3HT blends. ${ }^{40}$

Transient absorption (TA) measurements were further performed to quantify the yield of polaron generation upon charge transfer in the hybrid InP QDs/P3HT blends, following excitation at $400 \mathrm{~nm}$ with fluence of $15 \mu \mathrm{J} / \mathrm{cm}^{2}$. Transient spectra of neat P3HT and InP QDs/P3HT films at different time delays are compared in Figure 4. At $400 \mathrm{~nm}$, both P3HT and InP QDs absorb, and the spectra were recorded in the differential transmission mode $(\Delta T / T)$. Here the positive features in TA spectra correspond to ground state bleaching (GSB), revealing the characteristic vibronic structure of the P3HT film; negative features correspond to photoinduced absorption (PIA) mainly due to polarons arising from exciton dissociation at the hybrid interfaces. The corresponding kinetics of transient absorption signals for GSB and PIA are compared in Figure 5 and fitting parameters are shown in Table $S 3$ and S4. Comparing with pristine P3HT, the GSB kinetics of $\mathrm{InP}(2.5 \mathrm{~nm}) / \mathrm{P} 3 \mathrm{HT}$ thin film decays within the first $100 \mathrm{ps}$, suggesting that the electron transfer from $\mathrm{P} 3 \mathrm{HT}$ to $\operatorname{InP}(2.5$ $\mathrm{nm})$ is insufficient, even with pyridine ligands, likely due to trapping states induced by the ligand exchange on the surface of InP QD cores. In the case of $\operatorname{InP}(4.5 \mathrm{~nm}) / \mathrm{P} 3 \mathrm{HT}$, the GSB signal at $600 \mathrm{~nm}$ shows slow decay kinetics within $500 \mathrm{ps}$, which is an evidence for the formation of long-lived charges in this blend. The control sample of py- $\operatorname{InP}(4.5 \mathrm{~nm})$ was obtained by isolating QDs on the PMMA matrix. Figure S5 compares the ground state bleaching kinetics of py-InP( $4.5 \mathrm{~nm})$ in PMMA
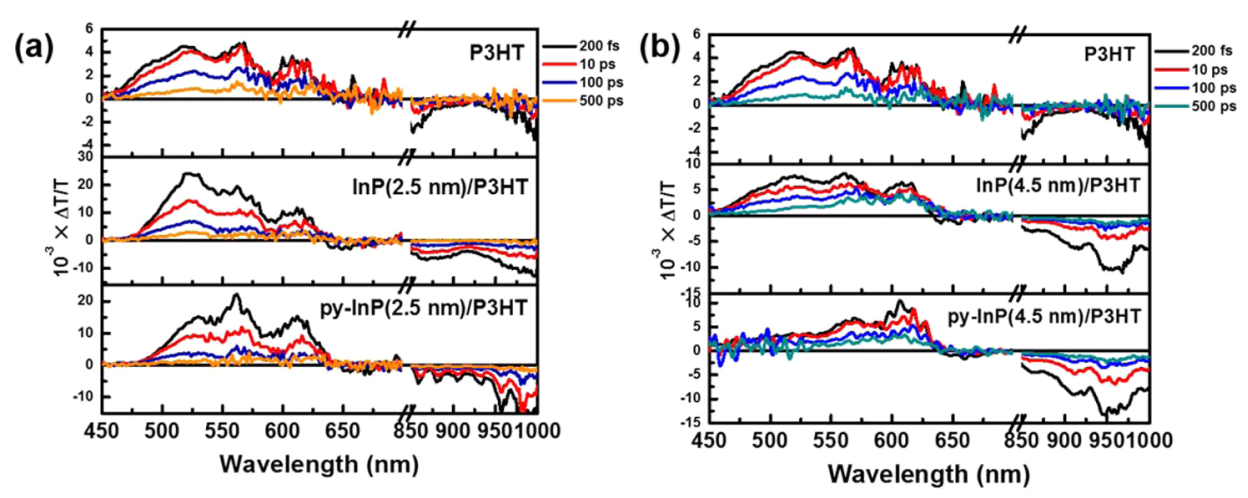

Figure 4. Transient absorption spectra of pristine P3HT: (a) $\operatorname{InP}(2.5 \mathrm{~nm})$ QDs/P3HT and (b) $\operatorname{InP}(4.5 \mathrm{~nm})$ QDs/P3HT before and after ligand exchange measured at $200 \mathrm{fs}, 10 \mathrm{ps}, 100 \mathrm{ps}$, and $500 \mathrm{ps}$ after excitation. Excitation: $400 \mathrm{~nm}, 15 \mu \mathrm{J} / \mathrm{cm}^{2}$. 

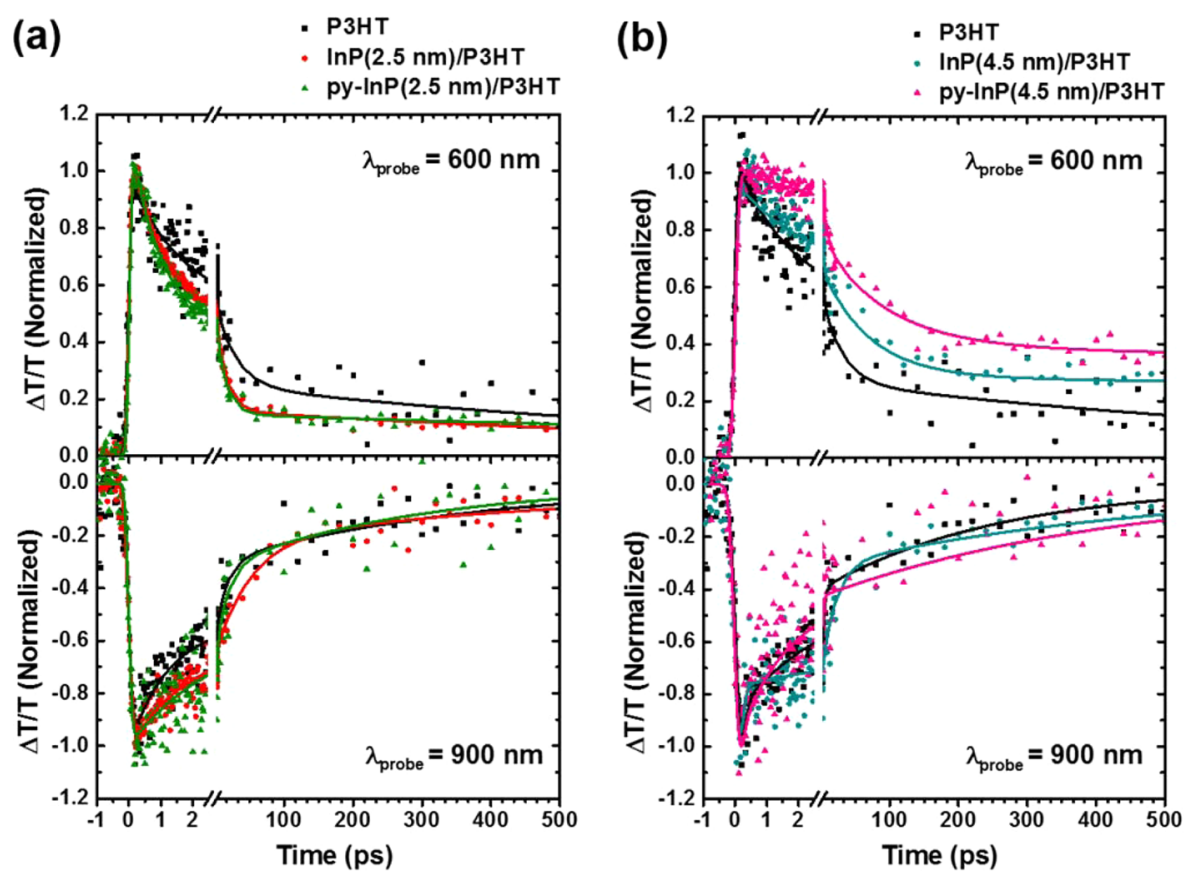

Figure 5. Comparison of kinetics of transient absorption signals for ground state bleaching $\left(\lambda_{\text {probe }}=600 \mathrm{~nm}\right)$ and polaron formation $\left(\lambda_{\text {probe }}=900\right.$ $\mathrm{nm})$ of P3HT and InP QDs/P3HT blends.

matrix and P3HT with same QDs concentration. As expected, the observed GSB signal $\left(\lambda_{\text {probe }}=550 \mathrm{~nm}\right)$ is very weak in the control sample, and dominant in InP/P3HT blend; observation of a long-lived GSB in InP/P3HT confirms the efficient electron injection from $\mathrm{P} 3 \mathrm{TH}$ to the InP QDs.

The PIA region between 850 and $1000 \mathrm{~nm}$, known as positive polaron absorption of $\mathrm{P} 3 \mathrm{HT}$, reveals additional differences between the hybrid blends and neat P3HT. In the absence of electron acceptor, excitons generated in the pure $\mathrm{P} 3 \mathrm{HT}$ film decay without forming polarons. Addition of $\mathrm{InP}(4.5 \mathrm{~nm})$ QDs to P3HT rapidly reduces the number of singlet excitons and also reveals a region of enhanced PIA signal. Since no detectable signal could be recorded in this spectral region in the control sample, we deduce that the PIA signal originates from the interaction of InP QDs and P3HT in the blend and conclude that the enhanced PIA features in $\mathrm{InP}(4.5 \mathrm{~nm}) / \mathrm{P} 3 \mathrm{HT}$ blend is due to the formation of P3HT hole polarons, generated by electrons transferred from polymer to the InP QDs. In the $\operatorname{InP}(2.5 \mathrm{~nm}) / \mathrm{P} 3 \mathrm{HT}$ blend, this polaron absorption is also present, albeit at a significantly reduced level. From a comparison of the $900 \mathrm{~nm}$ PIA signal magnitude in neat P3HT film and hybrid heterojunction, we infer that polaron yield increases by more than a factor of 2 in InP QDs/P3HT heterojunctions. Clearly, there is an ultrafast electron transfer from $\mathrm{P} 3 \mathrm{HT}$ to $\mathrm{InP}(4.5 \mathrm{~nm})$ QDs, a promising electron acceptor for hybrid photovoltaic devices. Finally, we assign the photoinduced absorption in this spectral range (1100-1300 $\mathrm{nm}$ ) to absorption by singlet excitons, in agreement with previous investigations. ${ }^{41}$ The kinetics probed at $1300 \mathrm{~nm}$ (Figure S4) also suggests that, independently of the choice of ligands, P3HT excitons are efficiently quenched by the InP QDs, in line with the photoluminescence kinetics in Figure $3 \mathrm{~b}$. The hybrid films exhibit a long-lived component that is fully absent in the neat polymer. This long-lived PIA is therefore related to the presence of QDs in the blends, which could arise from electronic transitions in the reduced InP QDs after charge transfer or from transitions from states akin to charge transfer states that involve positive polarons on the polymer chains and electrons on the QDs. Although there is a small signal in this $850-1000 \mathrm{~nm}$ region in the neat polymer films, its decay dynamics are similar to those of the singlet and polarons bands. Therefore, this neat polymer film signal can be separated from the large and long-lived signal observed in the hybrid films. In addition, both the prompt polymer bleach (observed at 600$800 \mathrm{~nm}$ ) and the prompt polaron signal are enhanced in the hybrid blends. This enhancement is due to higher yield of charge carriers (by a factor of $2-3$ at $1 \mathrm{ps}$ ), comparable to the yield estimated in $\mathrm{py}-\mathrm{InP}(4.5 \mathrm{~nm}) / \mathrm{P} 3 \mathrm{HT}$ hybrid heterojunctions. This observation and the concomitant increase of polaron absorption when P3HT is combined with InP QDs suggest the dissociation of singlet excitons being a precursor for polaron formation. We therefore conclude that the enhancement of polaron yield in $\mathrm{P} 3 \mathrm{HT}$ by adding $\operatorname{InP}(4.5 \mathrm{~nm})$ is due to an ultrafast electron transfer from $\mathrm{P} 3 \mathrm{HT}$ (electron donor) to InP (electron acceptor).

Quantum chemical calculations using a phonon-assisted full quantum treatment are used to elucidate the charge separation and recombination processes in these systems. Similar to the typical organic/organic system (P3HT:PCBM) shown in Figure $6 \mathrm{a}$, the calculated hole wave function in hybrid $\mathrm{QD} /$ polymer blends is localized along the P3HT molecule. This and other factors such as the presence of the spacer between the $\mathrm{QD}$ and the polymer, as well as the absence of actual chemical bonds or hybrid clusters, strongly reduce the possibility of direct charge generation in the InP QDs/P3HT blends. Conversely, the electron wave function is localized both at the InP core and on P3HT. This is indicative of charge transfer occurring at the InP/P3HT interface after photoexciation. Table 1 summarizes and compares the charge transfer and recombination rates at P3HT:PCBM and ideal $\mathrm{In}_{31} \mathrm{P}_{31} / \mathrm{P} 3 \mathrm{HT}$ interfaces (InP QD is fully passivated with hydrogen) calculated using nonradiative Marcus charge transfer theory. The average electronic coupling for charge separation $\left(V_{\mathrm{CS}}\right)$ between initial state (LUMO of P3HT) and final state (LUMO of InP QD) is 
(a)

P3HT:PCBM

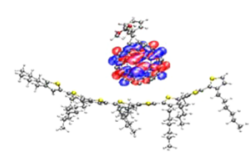

LUMO

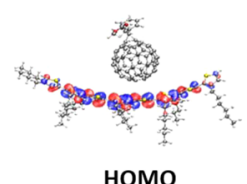

HOMO (b)

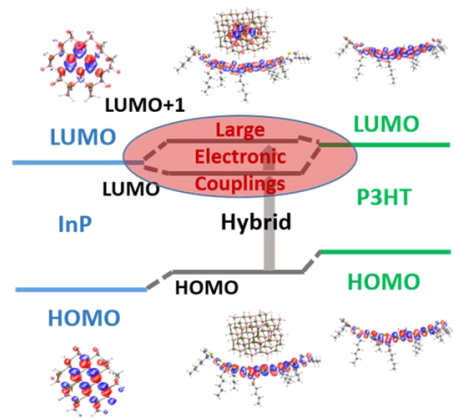

Figure 6. Energy level alignment and electronic distribution of HOMO and LUMO of (a) P3HT:PCBM and (b) $\operatorname{In}_{31} \mathrm{P}_{31} / \mathrm{P} 3 \mathrm{HT}$ interface with fully passivated $\mathrm{InP}$ with hydrogen. The isosurfaces are plotted with electron densities of $0.02 \mathrm{e} / \AA^{3}$.

15.2 meV, which is larger than that of the reference P3HT:PCBM system. The calculated electron transfer rate is $4.49 \times 10^{11} \mathrm{~s}^{-1}$ for $\operatorname{In}_{31} \mathrm{P}_{31}$, indicating efficient charge separation in InP QDs/P3HT hybrid system. This value is in good agreement with our pump-probe measurements $(<1 \mathrm{ps})$, demonstrating that the model of $\operatorname{In}_{31} \mathrm{P}_{31} / \mathrm{P} 3 \mathrm{HT}$ accurately captures the key features of the charge transfer dynamics. The predicted charge separation rate is larger by 3-4 orders than the charge recombination rate, in accordance with the time scale of electron injection from P3HT to InP QDs. Different from the ideal model (fully passivated InP QD), dangling bond defects or oxidation state on the surface may act as charge recombination centers in hybrid blends, resulting in increased charge recombination rate.

Finally, we propose a mechanism of charge and energy transfer at InP QDs/P3HT heterointerfaces, as shown in Figure 7. For $\operatorname{InP}(4.5 \mathrm{~nm}) / \mathrm{P} 3 \mathrm{HT}$ blend, electrons can be effectively injected from P3HT into InP QDs within 1 ps. This can be attributed to proper energy alignment and short spacing between InP cores and P3HT by replacing oleylamine ligand with pyridine. Electron injection is inefficient at the $\operatorname{InP}(2.5$ $\mathrm{nm}$ )/P3HT hybrid interface, probably due to the unfavorable interfacial energy alignment after ligand exchange. The enhancement of photoluminescence at $724 \mathrm{~nm}$ could result from either P3HT or $\operatorname{InP}(2.5 \mathrm{~nm})$ emission. Energy transfer from $\operatorname{InP}(2.5 \mathrm{~nm})$ to $\mathrm{P} 3 \mathrm{HT}$ may also increase the emission intensity of P3HT due to the overlap of P3HT absorption and $\operatorname{InP}(2.5 \mathrm{~nm})$ photoluminescence spectra, as shown in Figure $7 \mathrm{c}$.

In polymer/small QDs with short ligands, Dexter transfer is the dominating energy transfer mechanism. ${ }^{42}$ We evaluated the Dexter energy transfer rate for our systems according to $k_{\text {Dexter }}=$ $K J \exp \left(\left(-2 R_{D A}\right) / L\right)$, where $J$ is the normalized spectral overlap integral, $R_{\mathrm{DA}}$ is the calculated distance between the InP QD and $\mathrm{P} 3 \mathrm{HT}$, and $L$ is the van der Waals radius of P3HT (evaluated by the Polymorph code) and $K$ is a proportionality factor $(K=$ $2 / 3$ in the case of polymer/fullerene blends). ${ }^{43}$ For the py$\operatorname{InP}(2.5 \mathrm{~nm})$ QDs, we obtained $k_{\text {Dexter }}=1.83 \times 10^{13} \mathrm{~s}^{-1}$, which is indeed larger than the charge injection rate $\left(\sim 4.5 \times 10^{11} \mathrm{~s}^{-1}\right)$.

\section{CONCLUSIONS}

We presented a combined theoretical and experimental study of charge transfer in a rather unconventional polymer/III-V QD system. Our DFT calculations with nanoscale (diameter $<5$ $\mathrm{nm}$ ) InP QDs show strong quantum confinement, and predict that energy levels of ligand-InP complexes can be tuned by different organic ligands. Femtosecond time-resolved measurements were performed to elucidate the interfacial charge carrier dynamics at the InP QDs/P3HT system. For $\operatorname{InP}(4.5 \mathrm{~nm}) /$ $\mathrm{P} 3 \mathrm{HT}$, ultrafast electron injection from $\mathrm{P} 3 \mathrm{HT}$ into $\operatorname{InP}(4.5$ $\mathrm{nm}$ ) core can be concluded from dissociation of singlet exciton, enhancement of polaron absorption and large electronic coupling. Pyridine ligands facilitate this electron transfer process thanks to the short spacing between InP core and $\mathrm{P} 3 \mathrm{HT}$. In the case of $\operatorname{InP}(2.5 \mathrm{~nm}) / \mathrm{P} 3 \mathrm{HT}$, electron injection is inefficient but energy transfer takes place. The theoretical electron transfer rate predicted by Marcus theory can compete with that of organic/organic hybrid system, indicating that InP/ P3HT is an efficient charge separation system, provided that optimal InP QD size and organic ligands are used. Although the synthesis of III-V QDs remains challenging, our findings indicate that they are suitable alternatives to II-VI QDs for hybrid photovoltaic applications.

\section{MATERIALS AND METHODS}

Materials and Sample Preparation. regioregular P3HT and InP quantum dots were purchased from Rieke Metals and NN-lab, respectively, and used without further purification. To exchange the oleylamine ligands, the InP QDs were precipitated by addition of methanol and then isolated by centrifugation to obtain a solid pellet. Then a small amount of pyridine was added into the InP pellet and the resulting dispersion was heated gently at $60{ }^{\circ} \mathrm{C}$ under inert atmosphere overnight. Afterward, the pyridine modified InP QDs are precipitated with methanol, recovered by centrifugation and then dispersed in solvent of dichlorobenzene:pyridine (9:1 vol. ratio). InP QDs/polymer blend films with weight ratio of 3:1 (InP QDs: $30 \mathrm{mg} / \mathrm{mL}$ and P3HT: $10 \mathrm{mg} / \mathrm{mL}$ ) were spincoated at $800 \mathrm{rpm}$ under nitrogen atmosphere onto glass substrate for $60 \mathrm{~s}$. In absence of device data for III-V QD/ polymer solar cells, the weight ratio of 3:1 was chosen based on optimal conditions for II-VI/polymer blends, as they are expected to be similar. Before spin-coating, the glass substrates were cleaned by subsequent ultrasonic treatment in acetone, isopropanol and deionized water for $10 \mathrm{~min}$ each step. The images of atomic force microspectra (AFM) measurements of these InP QDs/P3HT thin film samples (in Figure S6) show large number of small domains, yielding large interfacial area between InP QDs and P3HT.

Infrared Absorption. FTIR absorption spectra were obtained by using Bruker Vertex 80v equipped with RTDTGS detector. Spectral and phase resolution used during Fourier transformation were 4 and $32 \mathrm{~cm}^{-1}$, respectively.

Steady-State Absorption and Photoluminescence. Steady-state absorption spectra were obtained by an UV-vis

Table 1. Calculated Parameters for Non-Radiative Charge Separation and Recombination Rates at P3HT:PCBM and In ${ }_{31} \mathbf{P}_{31} /$ P3HT Interfaces

\begin{tabular}{ccccccc} 
system & $S_{\text {eff }}$ & $G_{\mathrm{CS}} / G_{\mathrm{CR}}(\mathrm{eV})$ & $\lambda_{\text {ext }}(\mathrm{eV})$ & $\lambda_{\text {int }}(\mathrm{eV})$ & $V_{\mathrm{CS}} / V_{\mathrm{CR}}(\mathrm{meV})$ & $k_{\mathrm{CS}} / k_{\mathrm{CR}}\left(\mathrm{s}^{-1}\right)$ \\
\hline P3HT:PCBM & 1.38 & $-0.96 /-1.24$ & 0.26 & 0.320 & $13.8 / 19.6$ & $5.73 \times 10^{11} / 1.96 \times 10^{10}$ \\
$\mathrm{In}_{31} \mathrm{P}_{31} / \mathrm{P} 3 \mathrm{HT}$ & 1.36 & $-1.19 /-1.32$ & 0.12 & 0.316 & $15.2 / 18.4$ & $4.49 \times 10^{11} / 2.28 \times 10^{10}$
\end{tabular}


(a)

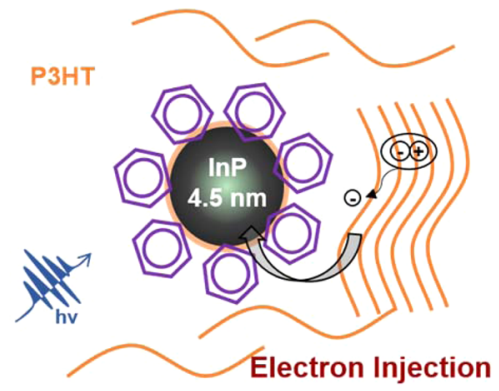

(b)

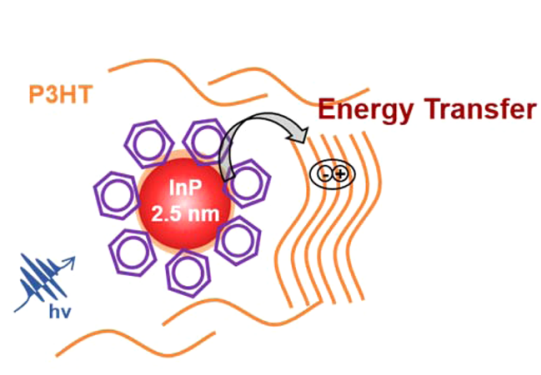

- Absorption of P3HT

(c) - Fluorescence of py-InP(2.5 nm)

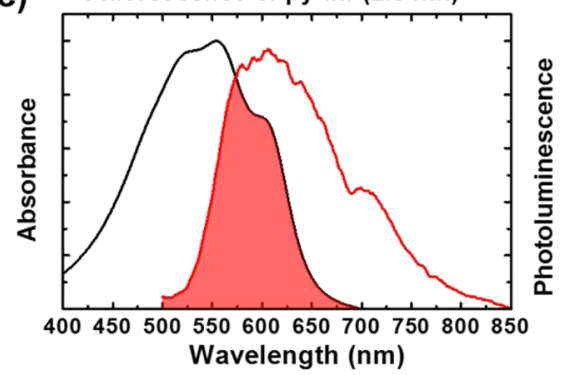

Figure 7. Proposed mechanism of (a) electron injection process between $\mathrm{P} 3 \mathrm{HT}$ and py-InP(4.5 nm), (b) energy transfer process between $\mathrm{P} 3 \mathrm{HT}$ and py-InP $(2.5 \mathrm{~nm})$, and (c) spectral overlap between absorption of $\mathrm{P} 3 \mathrm{HT}$ and photoluminescence of py-InP( $2.5 \mathrm{~nm})$.

spectrophotometer (Cary 100Bio, Varian) at $1.0 \mathrm{~nm}$ resolution, and the steady state photoluminescence spectra were recorded by a spectrofluorometer (Fluorolog-3, HORIBA Jobin Yvon).

Time-Resolved Photoluminescence. Fluorescence lifetime measurements were performed by time-correlated single photon counting (TCSPC) and by fluorescence upconversion. TCSPC measurements were conducted on a FluoTime 200 platform from Picoquant GmbH. A titanium-sapphire 100 fs laser (Chameleon, Coherent Inc. 100 fs pulse width, $80 \mathrm{MHz}$ repetition rate) combined with a harmonic generator was used as the excitation source with an excitation wavelength of 400 $\mathrm{nm}\left(I=8.5 \mathrm{~nJ} / \mathrm{cm}^{2}\right)$. The detector was a microchannel plate (MCP) PMT system HAM-R3809U-50 (Hamamatsu) with spectral sensitivity from 200 to $850 \mathrm{~nm}$ and instrument response function of $30 \mathrm{ps}$. Fluorescence up-conversion was measured with a FOG100, CDP spectrometer using $400 \mathrm{~nm}$ excitation femtosecond laser source (100 fs, $80 \mathrm{MHz})$. The fluorescence was collected by parabolic mirror and focused into a $0.5 \mathrm{~mm} \mathrm{BBO}$ crystal (cut angle 38, ooe interaction) together with the fundamental radiation $(800 \mathrm{~nm})$. The resulting sumfrequency radiation after passing through a double monochromator (CDP2022D) was detected by photomultiplierbased photoncounting electronics.

Transient Absorption Spectroscopy. Transient absorption experiments were carried out using a femtosecond pumpprobe setup where the excitation source was generated from the optical parametric amplifier (OPA). The second $(400 \mathrm{~nm})$ or third harmonic $(267 \mathrm{~nm})$ of the fundamental $(800 \mathrm{~nm})$ of a Ti:sapphire femtosecond laser (repetition rate $1 \mathrm{kHz}$, pulse width of $100 \mathrm{fs}$ and $2 \mathrm{~W}$ power) were used as pump, and white light was used as probe for measuring the transient absorption spectrum. The signals were collected and monitored using a monochromator/PMT configuration with lock-in detection. Third order nonlinear effects were minimized by setting the excitation density to a value $15 \mu \mathrm{J} / \mathrm{cm}^{2}$ per pulse. The entire measurements were performed on samples placed in a cryostat which was brought to pressure of $<10^{-3} \mathrm{~Pa}$.

\section{COMPUTATIONAL APPROACH}

Similar to the magic-sized $\mathrm{Cd}_{33} \mathrm{Se}_{33}$ structure, ${ }^{44}$ the InP QDs were constructed using $\operatorname{In}_{31} \mathrm{P}_{31}$ clusters with diameters of about $1.3 \mathrm{~nm}$ characterized with high stability, although magic-sized InP has not been experimentally reported yet. On the other hand, $\operatorname{In}_{31} \mathrm{P}_{31}$ model is large enough to exhibit the characteristic feature of a nanocrystal but are still feasible for ionic relaxation. The initial geometry of the $\operatorname{In}_{31} \mathrm{P}_{31}$ was obtained from the bulk structure using a spherical cutoff. Then the ligands were added to the optimized $\operatorname{In}_{31} \mathrm{P}_{31}$, and geometries of the combined ligand-capped InP systems were optimized. The geometries were optimized using the hybrid B3LYP functional with the LANL2DZ/6-31G* mixed basis set, where the LANL2DZ core pseudopotentials and associated valence basis sets were chosen for heavy In atoms and the 6-31G* all-electron basis set was assigned to other atoms $(\mathrm{H}, \mathrm{C}, \mathrm{N}, \mathrm{S}$, and $\mathrm{P}$ atoms $)$. The oligomers were considered to represent the low bandgap polymer P3HT (eight repeated units) based on the effective conjugated length of polythiophene as being between 6 and 12 units. The InP/P3HT interfacial structures were obtained from optimized molecular structures of P3HT and $\operatorname{In}_{31} \mathrm{P}_{31}$ and superimposing them to mimic the interfacial structures. The beginning intermolecuelar distance between $\mathrm{P} 3 \mathrm{HT}$ and $\mathrm{In}_{31} \mathrm{P}_{31}$ was set to be $3.5 \AA$. Here we only considered the thiophenes of $\mathrm{P} 3 \mathrm{HT}$ faced to InP surface because of the effective interactions between these donor-acceptor systems acquiring relatively larger electronic couplings.

Nonradiative Charge Transfer Rate. The rates of charge transfer between organic and inorganic hybrid systems can be approximately described by Marcus equation ${ }^{45}$ by the following equation $k=((2 \pi) / \hbar)|V|^{2}\left(1 /\left(4 \pi \lambda K_{B} T\right)^{1 / 2}\right) \exp \left(-\left(\lambda /\left(4 K_{B} T\right)\right)\right)$ in the high-temperature limit, where $T$ is the temperature, $k$ and $\hbar$ refer to the Boltzman and Planck constants, respectively, $\lambda$ is the electron reorganization energy due to geometric relaxation accompanying charge transfer, and $V$ is the electronic coupling matrix element between the interesting frontier orbitals of donor and acceptor. In lower temperature, it is appropriate to 
use the Marcus-Levitch-Jortner (MLJ) equation formulation of the rate expression containing the effect of the quantum vibrational modes: ${ }^{46}$

$$
\begin{aligned}
k= & \frac{2 \pi}{\hbar}|V|^{2} \frac{1}{\sqrt{4 \pi \lambda_{\text {ext }} K_{\mathrm{B}} T}} \sum_{v} \exp \left(-S^{e f f}\right) \frac{\left(S^{e f f}\right)^{v}}{v !} \\
& \exp \left(-\frac{\left(\lambda_{\text {ext }}+v \hbar \omega^{\text {eff }}+\Delta G\right)^{2}}{4 \lambda_{\text {ext }} K_{\mathrm{B}} T}\right)
\end{aligned}
$$

where $S^{\text {eff }}$ is the effective Huang-Ryhs factor and $\omega^{\text {eff }}$ is the frequency of one effective mode that incorporates the effect of all the quantum modes in an average way. $\Delta G$ is the Gibbs free energy between the initial and final states.

Internal and External Reorganization Energy. The reorganization energy $(\lambda)$ can be separated into the internal reorganization energy $\left(\lambda_{\text {int }}\right)$ and external reorganization energy $\left(\lambda_{\text {ext }}\right) . \lambda_{\text {int }}$ is normally further decomposed into contributions along the various normal frequency modes of the molecule according to $\lambda_{\text {int }}=\sum S_{i} \hbar \omega_{i}$, where $S_{i}$ is the Huang-Rhys factor of the corresponding frequency mode, describing the electronvibration coupling strength in terms of the projection along the normal mode of the displacement between the equilibrium of initial and final geometry. The analysis of the electron transfer rate was greatly simplified by defining effective frequency $\omega_{\text {eff }}$ and effective Huang-Ryes factor $S_{\text {eff }}=\sum_{i} S_{i} \hbar \omega_{i} / \omega_{\text {eff }}$. The calculations of the Huang-Rhys factors were carried out with the DUSHIN program. ${ }^{47}$

The $\lambda_{\text {ext }}$ empirical formula can be expressed as

$$
\begin{aligned}
& \lambda_{\text {ext }}=\frac{(\Delta q)^{2}}{2}\left(\frac{1}{\sqrt[3]{\left(R_{x} R_{y} R_{z}\right)_{D}}}+\frac{1}{\sqrt[3]{\left(R_{x} R_{y} R_{z}\right)_{A}}}-\frac{2}{l_{D A}}\right) \\
& \left(\frac{1}{\varepsilon_{\text {opt }}}-\frac{1}{\varepsilon_{S}}\right)
\end{aligned}
$$

where $\Delta q$ is the transferred charge and $R_{\mathrm{i}}$ are the semiaxes of the ellipses that separately encompass the donor and acceptor: 7.91, 5.41, and 7.88 $\AA$ for $\operatorname{In}_{31} \mathrm{P}_{31}$ and 14.59, 5.43, and 7.84 $\AA$ for P3HT. The $l_{\mathrm{DA}}=10.08 \AA$ is the center-to-center distance between donor and acceptor, and $\varepsilon_{\mathrm{opt}}$ and $\varepsilon_{\mathrm{s}}$ are the optical and static dielectric constants of the surrounding P3HT matrix ${ }^{48}$ by using experimental values of $\varepsilon_{\text {opt }}=1.96$ and $\varepsilon_{\mathrm{s}}=3.3$. $^{49}$

Electronic Couplings. The electronic coupling $V_{\mathrm{ij}}$, which is defined as $\left\langle\phi_{i}|\hat{F}| \phi_{j}\right\rangle$, between the $\phi_{i}$ and $\phi_{j}$ orbitals of the isolated donor and acceptor fragments can be calculated by projecting the Fock Matrix of dimer onto molecular orbitals of respective donor and acceptor molecule with the subsequent symmetric orthogonalization, where $\hat{F}$ is the Kohn-Sham Fock operator of the whole system. The electronic coupling in the charge separation process $\left(V_{\mathrm{cs}}\right)$ is taken to be the coupling between the LUMO of P3HT and $\operatorname{In}_{31} \mathrm{P}_{31}$. The electronic coupling in the charge recombination process $\left(V_{\mathrm{CR}}\right)$ is taken to be the coupling between HOMO of P3HT and LUMO of $\mathrm{In}_{31} \mathrm{P}_{31}$.

Gibbs Free Energy. The Gibbs free energy for charge recombination $\left(\Delta G_{\mathrm{CR}}\right)$ and separation $\left(\Delta G_{\mathrm{CS}}\right)$ can be calculated as the energy changes of isolated donor and acceptor, where the $\Delta G_{C S}=E_{D}^{+}+E_{A}^{-}+E_{C}-E_{D}^{0}-E_{A}^{0}-$ $E_{g}^{o p t}$, and $\Delta G_{C R}=E_{D}^{0}+E_{A}^{0}-E_{D}^{+}-E_{A}^{-}-E_{C}$, where $E_{D}^{+/ 0}$ and $E_{A}^{-/ 0}$ are ionic/ground state energy of donor and acceptor, $E_{C}$ is the
Coulomb stabilization energy, and $E_{g}^{\text {opt }}$ is the optical gap of the donor.

\section{ASSOCIATED CONTENT}

\section{S Supporting Information}

The Supporting Information is available free of charge on the ACS Publications website at DOI: 10.1021/acs.jpcc.5b09397.

$\mathrm{X}$-ray photoelectron spectroscopy of $\mathrm{P} 2 \mathrm{p}$, photoluminescence spectra of InP QDs in solvent, kinetics of exciton band, and atomic force microspectra images of P3HT and InP QDs/P3HT thin films (PDF)

\section{AUTHOR INFORMATION}

\section{Corresponding Author}

*(C.S.) E-mail: csoci@ntu.edu.sg.

\section{Present Address}

$\S$ (S.S.K.R) Department of Physics, Indian Institute of Technology Hyderabad, Yeddumailaram 502205, Telengana, India.

\section{Notes}

The authors declare no competing financial interest.

\section{ACKNOWLEDGMENTS}

Research was supported by the Singapore Ministry of Education (MOE2013-T2-1-044) and the Singapore-Berkeley Research Initiative for Sustainable Energy (SinBeRISE) Create Programme. The authors are grateful to Dr. Chen Shi for the XPS measurements and to Dr. Annalisa Bruno for useful discussions.

\section{REFERENCES}

(1) Huynh, W. U.; Dittmer, J. J.; Alivisatos, A. P. Hybrid NanorodPolymer Solar Cells. Science 2002, 295, 2425-2427.

(2) Tang, J.; Kemp, K. W.; Hoogland, S.; Jeong, K. S.; Liu, H.; Levina, L.; Furukawa, M.; Wang, X.; Debnath, R.; Cha, D.; et al. Colloidal-Quantum-Dot Photovoltaics Using Atomic-Ligand Passivation. Nat. Mater. 2011, 10, 765-771.

(3) Sandeep, C. S. S.; Ten Cate, S.; Schins, J. M.; Savenije, T. J.; Liu, Y.; Law, M.; Kinge, S.; Houtepen, A. J.; Siebbeles, L. D. A. High Charge-Carrier Mobility Enables Exploitation of Carrier Multiplication in Quantum-Dot Films. Nat. Commun. 2013, 4, 2360.

(4) Schaller, R. D.; Klimov, V. I. High Efficiency Carrier Multiplication in Pbse Nanocrystals: Implications for Solar Energy Conversion. Phys. Rev. Lett. 2004, 92, 186601.

(5) Tan, Y. Z.; Jin, S.; Hamers, R. J. Photostability of CdSe Quantum Dots Functionalized with Aromatic Dithiocarbamate Ligands. ACS Appl. Mater. Interfaces 2013, 5, 12975-12983.

(6) Li, Z.; Gao, F.; Greenham, N. C.; McNeill, C. R. Comparison of the Operation of Polymer/Fullerene, Polymer/Polymer, and Polymer/ Nanocrystal Solar Cells: A Transient Photocurrent and Photovoltage Study. Adv. Funct. Mater. 2011, 21, 1419-1431.

(7) Liu, C. Y.; Holman, Z. C.; Kortshagen, U. R. Hybrid Solar Cells from P3HT and Silicon Nanocrystals. Nano Lett. 2009, 9, 449-452.

(8) Herrmann, D.; Niesar, S.; Scharsich, C.; Kohler, A.; Stutzmann, M.; Riedle, E. Role of Structural Order and Excess Energy on Ultrafast Free Charge Generation in Hybrid Polythiophene/Si Photovoltaics Probed in Real Time by near-Infrared Broadband Transient Absorption. J. Am. Chem. Soc. 2011, 133, 18220-18233.

(9) Beek, W. J. E.; Wienk, M. M.; Janssen, R. A. J. Hybrid Solar Cells from Regioregular Polythiophene and $\mathrm{ZnO}$ Nanoparticles. Adv. Funct. Mater. 2006, 16, 1112-1116.

(10) Greaney, M. J.; Das, S.; Webber, D. H.; Bradforth, S. E.; Brutchey, R. L. Improving Open Circuit Potential in Hybrid P3HT:CdSe Bulk Heterojunction Solar Cells Via Colloidal TertButylthiol Ligand Exchange. ACS Nano 2012, 6, 4222-4230. 
(11) Cappel, U. B.; Dowland, S. A.; Reynolds, L. X.; Dimitrov, S.; Haque, S. A. Charge Generation Dynamics in Cds:P3HT Blends for Hybrid Solar Cells. J. Phys. Chem. Lett. 2013, 4, 4253-4257.

(12) Grancini, G.; Biasiucci, M.; Mastria, R.; Scotognella, F.; Tassone, F.; Polli, D.; Gigli, G.; Lanzani, G. Dynamic Microscopy Study of Ultrafast Charge Transfer in a Hybrid P3HT/Hyperbranched CdSe Nanoparticle Blend for Photovoltaics. J. Phys. Chem. Lett. 2012, 3, 517-523.

(13) Piliego, C.; Manca, M.; Kroon, R.; Yarema, M.; Szendrei, K.; Andersson, M. R.; Heiss, W.; Loi, M. A. Charge Separation Dynamics in a Narrow Band Gap Polymer-Pbs Nanocrystal Blend for Efficient Hybrid Solar Cells. J. Mater. Chem. 2012, 22, 24411-24416.

(14) Jarzab, D.; Szendrei, K.; Yarema, M.; Pichler, S.; Heiss, W.; Loi, M. A. Charge-Separation Dynamics in Inorganic-Organic Ternary Blends for Efficient Infrared Photodiodes. Adv. Funct. Mater. 2011, 21, 1988-1992.

(15) Gocalinska, A.; Saba, M.; Quochi, F.; Marceddu, M.; Szendrei, K.; Gao, J.; Loi, M. A.; Yarema, M.; Seyrkammer, R.; Heiss, W.; et al. Size-Dependent Electron Transfer from Colloidal Pbs Nanocrystals to Fullerene. J. Phys. Chem. Lett. 2010, 1, 1149-1154.

(16) Jeltsch, K. F.; Schadel, M.; Bonekamp, J. B.; Niyamakom, P.; Rauscher, F.; Lademann, H. W. A.; Dumsch, I.; Allard, S.; Scherf, U.; Meerholz, K. Efficiency Enhanced Hybrid Solar Cells Using a Blend of Quantum Dots and Nanorods. Adv. Funct. Mater. 2012, 22, 397-404.

(17) Zhou, R. J.; Stalder, R.; Xie, D. P.; Cao, W. R.; Zheng, Y.; Yang, Y. X.; Plaisant, M.; Holloway, P. H.; Schanze, K. S.; Reynolds, J. R.; et al. Enhancing the Efficiency of Solution-Processed Polymer:Colloidal Nanocrystal Hybrid Photovoltaic Cells Using Ethanedithiol Treatment. ACS Nano 2013, 7, 4846-4854.

(18) Yuan, J. Y.; Gallagher, A.; Liu, Z. K.; Sun, Y. X.; Ma, W. L. HighEfficiency Polymer-Pbs Hybrid Solar Cells Via Molecular Engineering. J. Mater. Chem. A 2015, 3, 2572-2579.

(19) Rhee, J. H.; Chung, C. C.; Diau, E. W. G. A Perspective of Mesoscopic Solar Cells Based on Metal Chalcogenide Quantum Dots and Organometal-Halide Perovskites. NPG Asia Mater. 2013, 5, e68.

(20) Brown, P. R.; Kim, D.; Lunt, R. R.; Zhao, N.; Bawendi, M. G.; Grossman, J. C.; Bulovic, V. Energy Level Modification in Lead Sulfide Quantum Dot Thin Films through Ligand Exchange. ACS Nano 2014, $8,5863-5872$.

(21) Nagaoka, H.; Colbert, A. E.; Strein, E.; Janke, E. M.; Salvador, M.; Schlenker, C. W.; Ginger, D. S. Size-Dependent Charge Transfer Yields in Conjugated Polymer/Quantum Dot Blends. J. Phys. Chem. C 2014, 118, 5710-5715.

(22) Frederick, M. T.; Amin, V. A.; Swenson, N. K.; Ho, A. Y.; Weiss, E. A. Control of Exciton Confinement in Quantum Dot-Organic Complexes through Energetic Alignment of Interfacial Orbitals. Nano Lett. 2013, 13, 287-292.

(23) Frederick, M. T.; Amin, V. A.; Weiss, E. A. Optical Properties of Strongly Coupled Quantum Dot-Ligand Systems. J. Phys. Chem. Lett. 2013, 4, 634-640.

(24) Xie, R.; Battaglia, D.; Peng, X. Colloidal Inp Nanocrystals as Efficient Emitters Covering Blue to near-Infrared. J. Am. Chem. Soc. 2007, 129, 15432-15433.

(25) Harris, D. K.; Bawendi, M. G. Improved Precursor Chemistry for the Synthesis of III-V Quantum Dots. J. Am. Chem. Soc. 2012, 134, 20211-20213

(26) Couderc, E.; Greaney, M. J.; Brutchey, R. L.; Bradforth, S. E. Direct Spectroscopic Evidence of Ultrafast Electron Transfer from a Low Band Gap Polymer to CdSe Quantum Dots in Hybrid Photovoltaic Thin Films. J. Am. Chem. Soc. 2013, 135, 18418-18426.

(27) Strein, E.; deQuilettes, D. W.; Hsieh, S. T.; Colbert, A. E.; Ginger, D. S. Hot Hole Transfer Increasing Polaron Yields in Hybrid Conjugated Polymer/Pbs Blends. J. Phys. Chem. Lett. 2014, 5, 208211.

(28) Blackburn, J. L.; Ellingson, R. J.; Micic, O. I.; Nozik, A. J. Electron Relaxation in Colloidal Inp Quantum Dots with Photogenerated Excitons or Chemically Injected Electrons. J. Phys. Chem. B 2003, 107, 102-109.
(29) Blackburn, J. L.; Selmarten, D. C.; Ellingson, R. J.; Jones, M.; Micic, O.; Nozik, A. J. Electron and Hole Transfer from Indium Phosphide Quantum Dots. J. Phys. Chem. B 2005, 109, 2625-2631.

(30) Selmarten, D.; Jones, M.; Rumbles, G.; Yu, P. R.; Nedeljkovic, J.; Shaheen, S. Quenching of Semiconductor Quantum Dot Photoluminescence by a Pi-Conjugated Polymer. J. Phys. Chem. B 2005, 109, 15927-15932.

(31) Li, H. S.; Wu, Z. G.; Lusk, M. T. Dangling Bond Defects: The Critical Roadblock to Efficient Photoconversion in Hybrid Quantum Dot Solar Cells. J. Phys. Chem. C 2014, 118, 46-53.

(32) Tarafder, K.; Surendranath, Y.; Olshansky, J. H.; Alivisatos, A. P.; Wang, L.-W. Hole Transfer Dynamics from a CdSe/Cds Quantum Rod to a Tethered Ferrocene Derivative. J. Am. Chem. Soc. 2014, 136, 5121-5131.

(33) Peterson, M. D.; Cass, L. C.; Harris, R. D.; Edme, K.; Sung, K.; Weiss, E. A. The Role of Ligands in Determining the Exciton Relaxation Dynamics in Semiconductor Quantum Dots. Annu. Rev. Phys. Chem. 2014, 65, 317-339.

(34) Lee, J. R. I.; Whitley, H. D.; Meulenberg, R. W.; Wolcott, A.; Zhang, J. Z.; Prendergast, D.; Lovingood, D. D.; Strouse, G. F.; Ogitsu, T.; Schwegler, E.; et al. Ligand-Mediated Modification of the Electronic Structure of CdSe Quantum Dots. Nano Lett. 2012, 12, 2763-2767.

(35) Micic, O. I.; Ahrenkiel, S. P.; Nozik, A. J. Synthesis of Extremely Small Inp Quantum Dots and Electronic Coupling in Their Disordered Solid Films. Appl. Phys. Lett. 2001, 78, 4022-4024.

(36) Dung, M. X.; Mohapatra, P.; Choi, J. K.; Kim, J. H.; Jeong, S.; Jeong, H. D. Inp Quantum Dot-Organosilicon Nanocomposites. Bull. Korean Chem. Soc. 2012, 33, 1491-1504.

(37) Virieux, H.; Le Troedec, M.; Cros-Gagneux, A.; Ojo, W. S.; Delpech, F.; Nayral, C.; Martinez, H.; Chaudret, B. Inp/Zns Nanocrystals: Coupling Nmr and Xps for Fine Surface and Interface Description. J. Am. Chem. Soc. 2012, 134, 19701-19708.

(38) Sharma, S. N.; Vats, T.; Dhenadhayalan, N.; Ramamurthy, P.; Narula, A. K. Ligand-Dependent Transient Absorption Studies of Hybrid Polymer:CdSe Quantum Dot Composites. Sol. Energy Mater. Sol. Cells 2012, 100, 6-15.

(39) Banerji, N.; Cowan, S.; Vauthey, E.; Heeger, A. J. Ultrafast Relaxation of the Poly(3-hexylthiophene) Emission Spectrum. J. Phys. Chem. C 2011, 115, 9726-9739.

(40) Firdaus, Y.; Miranti, R.; Fron, E.; Khetubol, A.; Vandenplas, E.; Cheyns, D.; Borchert, H.; Parisi, J.; Van der Auweraer, M. Charge Separation Dynamics at Bulk Heterojunctions between Poly(3hexylthiophene) and Pbs Quantum Dots. J. Appl. Phys. 2015, 118, 055502.

(41) Tamai, Y.; Matsuura, Y.; Ohkita, H.; Benten, H.; Ito, S. OneDimensional Singlet Exciton Diffusion in Poly(3-hexylthiophene) Crystalline Domains. J. Phys. Chem. Lett. 2014, 5, 399-403.

(42) Hoffman, J. B.; Choi, H.; Kamat, P. V. Size-Dependent Energy Transfer Pathways in CdSe Quantum Dot-Squaraine Light-Harvesting Assemblies: Forster Versus Dexter. J. Phys. Chem. C 2014, 118, 18453-18461.

(43) Armaroli, N.; Barigelletti, F.; Ceroni, P.; Eckert, J. F.; Nicoud, J. F.; Nierengarten, J. F. Photoinduced Energy Transfer in a FullereneOligophenylenevinylene Conjugate. Chem. Commun. 2000, 599-600.

(44) Del Ben, M.; Havenith, R. W. A.; Broer, R.; Stener, M. Density Functional Study on the Morphology and Photoabsorption of CdSe Nanoclusters. J. Phys. Chem. C 2011, 115, 16782-16796.

(45) Marcus, R. A. The 2nd Robinson,R.A. Memorial Lecture Electron, Proton and Related Transfers. Faraday Discuss. Chem. Soc. 1982, 74, 7-15.

(46) Barbara, P. F.; Meyer, T. J.; Ratner, M. A. Contemporary Issues in Electron Transfer Research. J. Phys. Chem. 1996, 100, 1314813168.

(47) Reimers, J. R. A Practical Method for the Use of Curvilinear Coordinates in Calculations of Normal-Mode-Projected Displacements and Duschinsky Rotation Matrices for Large Molecules. J. Chem. Phys. 2001, 115, 9103-9109. 
(48) Marcus, R. A. On the Theory of Oxidation-Reduction Reactions Involving Electron Transfer 0.1. J. Chem. Phys. 1956, 24, 966-978.

(49) Liu, T.; Troisi, A. Absolute Rate of Charge Separation and Recombination in a Molecular Model of the P3HT/PCBM Interface. J.

Phys. Chem. C 2011, 115, 2406-2415. 